\title{
Intestinal Epithelial Cells Regulate Gut Eotaxin Responses and Severity of Allergy
}

\author{
Eunsoo Kim ${ }^{1}$, Melanie Lembert', Ghaith M. Fallata ${ }^{2}$, John C. Rowe', Tara L. Martin', \\ Abhay R. Satoskar ${ }^{3}$, Nicholas V. Reo ${ }^{2}$, Oleg Paliy' ${ }^{2}$, Estelle Cormet-Boyaka ${ }^{1}$ and \\ Prosper N. Boyaka ${ }^{1 *}$
}

${ }^{1}$ Department of Veterinary Biosciences, The Ohio State University, Columbus, OH, United States, ${ }^{2}$ Department of Biochemistry and Molecular Biology, Boonshoft School of Medicine, Wright State University, Dayton, OH, United States, ${ }^{3}$ Department of Pathology, The Ohio State University, Columbus, $\mathrm{OH}$, United States

OPEN ACCESS

Edited by:

Eric Cox,

Ghent University, Belgium

Reviewed by:

Claudio Nicoletti,

Università degli Studi di

Firenze, Italy

Hun Sik Kim

University of Ulsan College of Medicine, South Korea

*Correspondence: Prosper N. Boyaka boyaka.1@osu.edu

Specialty section:

This article was submitted

to Mucosal Immunity,

a section of the journal

Frontiers in Immunology

Received: 22 April 2018

Accepted: 10 July 2018

Published: 03 August 2018

Citation:

Kim E, Lembert M, Fallata GM, Rowe JC, Martin TL, Satoskar AR, Reo NV, Paliy O, Cormet-Boyaka E

and Boyaka PN (2018) Intestinal Epithelial Cells Regulate Gut Eotaxin Responses and Severity of Allergy.

Front. Immunol. 9:1692. doi: 10.3389/fimmu.2018.01692
Intestinal epithelial cells (IECs) are known to regulate allergic sensitization. We addressed the role of the intrinsic IKK $\beta$ signaling in IECs in the effector phase of allergy following oral allergen challenge and its impact on the severity of responses is poorly. Upon orally sensitization by co-administration of ovalbumin with cholera toxin as adjuvant, wildtype and mice lacking IKK $\beta$ in IECs (IKK $\beta^{\Delta I E C}$ mice) developed similar levels of serum IgE and allergen-specific secretory IgA in the gut. However, subsequent allergen challenges in the gut promoted allergic lower responses in $\mathrm{KK} \beta^{\Delta \mathrm{EC}}$ mice. Analysis of cytokines and chemokines in serum and gut tissues after oral allergen challenge revealed impaired eotaxin responses in IKK $\beta^{\Delta I E C}$ mice, which correlated with lower frequencies of eosinophils in the gut lamina propria. We also determined that IECs were a major source of eotaxin and that impaired eotaxin production was due to the lack of IKK $\beta$ signaling in IECs. Oral administration of CCL11 to IKK $\beta^{\Delta I E C}$ mice during oral allergen challenge enhanced allergic responses to levels in wild-type mice, confirming the role of IECderived eotaxin as regulator of the effector phase of allergy following allergen challenge. Our results identified targeting IEC-derived eotaxin as potential strategy to limit the severity of allergic responses to food antigens.

Keywords: intestinal epithelial cells, allergy, eotaxins, NF-кB, eosinophils

\section{INTRODUCTION}

Food allergy is a hypersensitive reaction against harmless food materials such as cow's milk, hen's egg, or peanut, to name a few $(1,2)$. Food allergy can be acquired after loss of immunological tolerance (mucosal tolerance) to food antigens. Because of shared moieties, sensitization to food allergens can also lead to allergies to environmental, plant, or other unrelated products (3). According to the CDC report, young students who have food allergy also have higher incidence of other allergies such as asthma or dermatitis (4). Incidence of allergies is growing $(2,3,5)$ and environmental factors, including pollutants, drugs, antibiotics, and stress are believed to contribute to this trend.

Allergic responses occur after a cascade of events that can be divided into a sensitization or priming phase, which is when the host develops adaptive immune responses against the allergens, and an effector phase. The effector phase generates the clinical signs of allergy and is triggered by the re-exposure of cells and molecules of the adaptive immunity to the allergens. Allergic symptoms are different according to the sites where allergic responses occur, but most of the food allergic responses are associated with IgE, mast cell degranulation, and eosinophilia (6). Intestinal epithelial cells 
(IECs) are the first cells encountered by ingested allergens. The role of these cells in allergy was initially believed to be restricted to the regulation of intestinal permeability to luminal content. It is now well established that IECs produce cytokines, including IL-25, IL-33, and thymic stromal lymphopoietin (TSLP), which help the development of Th2 cells necessary for production of $\operatorname{IgE}$ and allergic responses (7-10). The nuclear factor- $\kappa \mathrm{B}$ $(\mathrm{NF}-\mathrm{kB})$ pathway was shown to play a major role in cytokine production by IECs. In this regard, NF- $\kappa \mathrm{B}$ is a transcriptional factor that regulates immunological response including inflammation and lymphoid organogenesis (11). Signals through the canonical NF- $\kappa$ B pathways are regulated by the inhibitor $-\kappa B$ kinase (IKK $\beta$ ) (12). We have previously shown that cell-specific ablation of IKK $\beta$ in IECs (IKK $\beta^{\Delta \mathrm{IEC}}$ mice) alters the profile of allergen-specific T helper cells responses (13). These studies also showed that orally sensitized IKK $\beta^{\triangle \mathrm{IEC}}$ mice develop lower levels of allergic lung inflammation than their wild-type counterpart after nasal allergen challenge (13). The protective effect observed in IKK $\beta^{\Delta I E C}$ mice correlated with higher levels of allergen-specific $\operatorname{IgA}$ in the lungs and bronchoalveolar lavages suggesting that allergen-specific IgA present in the airways limited the extent of allergic airway inflammation in these mice (13). However, it remains unclear whether allergen-specific secretory IgA (SIgA) present in the intestinal lumen and in gut-associated lymphoid tissues could also prevent or limit the severity of allergic inflammation in the gastrointestinal (GI) tract. Also unclear is how the lack of IKK $\beta$ in IECs impacts the effector phase of allergic responses after oral allergen challenge and the development of clinical signs of allergy.

Using the well-established model of oral sensitization in the presence of cholera toxin (CT) as adjuvant (13-15), we addressed the role of IECs during the effector phase of allergy response subsequent to oral allergen challenge. Our data show that lack of IKK $\beta$ in IECs prevents the development of allergic responses and identifies the NF- $\kappa \mathrm{B}$ eotaxin axis as a mechanism through which IECs regulate the severity of allergic responses to ingested allergens.

\section{RESULTS}

\section{Lack of Intestinal Epithelial Cell-Intrinsic IKK $\beta$ Lowers Allergic Responses to Ingested Antigens}

To address the role of intestinal epithelial cell IKK $\beta$ in allergic responses in the gut, age-matched wild-type $\mathrm{C} 57 \mathrm{BL} / 6$ and IKK $\beta^{\triangle \mathrm{IEC}}$ mice were co-housed and orally sensitized by administration of ovalbumin (OVA) and CT as adjuvant, and then orally challenged with OVA alone (Figure 1A). Since IKK $\beta^{\triangle I E C}$ mice are defective in canonical NF- $\kappa \mathrm{B}$ pathway signaling in IECs, we first examined whether a compensatory pathway occurred in the gut of these mice. Analysis of gut tissues revealed activation of the non-canonical NF- $\mathrm{BB}$ pathway in intestinal villi and crypts of IKK $\beta^{\triangle I E C}$ mice that was not observed in the wild-type counterpart (Figure 1B). It is worth noting that p52 NF- $\kappa \mathrm{B}$ was not detected in the Peyer's patches (Figure 1C), which suggests that activation of non-canonical NF- $\kappa B$ in IKK $\beta^{\Delta \mathrm{IEC}}$ mice is restricted to epithelial cells. The lack of canonical NF- $\mathrm{BB}$ signaling and subsequent activation of the non-canonical NF- $\kappa B$ in IKK $\beta^{\Delta I E C}$ mice did not affect allergic sensitization since wild-type and IKK $\beta^{\Delta \mathrm{IEC}}$ mice developed similar levels of allergen-specific IgE responses following oral sensitization (Figure 1D).

Oral allergen challenge of sensitized mice induced a significant drop of body temperature in wild-type mice (Figure 1E), which was consistent with a significant change in behavior. Thus, these mice showed signs of allergy (i.e., low activity, scratching of nose and mouth, and self-isolation) with an average clinical score of 2.5 (Figure 1F) and high histamine levels in the serum (Figure 1G). Consistent with the fact that allergic reactions can occur at distant mucosal sites following ingestion of food antigen, high levels of histamine were also detected in the BAL fluids (Figure 1G). Despite containing similar levels of allergenspecific serum IgE to control wild-type mice, the IKK $\beta^{\Delta \mathrm{IEC}}$ mice exhibited a significantly lower drop in body temperature following oral allergen challenge, which was in line with their significantly lower clinical signs of allergy and histamine levels (Figures 1E-G).

\section{Allergen-Specific SIgA Unlikely Reduces the Severity of Allergy in IKK ${ }^{\Delta \mathrm{IEC}}$ Mice Following Oral Allergen Challenge}

Secretory IgA are believed to limit the entry of pathogens and allergens into the host (16). Accordingly, the presence of allergen-specific IgA in the BAL was shown to correlate with lower levels of allergic inflammation in IKK $\beta^{\Delta \mathrm{IEC}}$ mice after nasal allergen challenge (13). As previously reported, oral sensitization induced higher levels of allergen-specific serum IgA in IKK $\beta^{\Delta I E C}$ mice (Figure 2A). The total amounts of IgA measured in fecal extracts were significantly higher in IKK $\beta^{\triangle \mathrm{IEC}}$ mice at days 14 and 21 (Figure 2B). Surprisingly, no difference was noted between OVA-specific SIgA responses in fecal extract of IKK $\beta^{\Delta I E C}$ and control wild-type mice.

Since SIgA levels failed to provide clues on how IKK $\beta^{\Delta \mathrm{IEC}}$ mice only developed minimal signs of allergic responses following oral allergen challenge, we analyzed cytokines present in the serum of these mice. No significant difference was noted between the levels of Th1 cytokines (i.e., IFN $\gamma, \mathrm{TNF} \alpha$ ) in the serum of control wild-type and IKK $\beta^{\Delta \mathrm{IEC}}$ mice following oral allergen challenge (Figure 2C). Interestingly, serum Th2 cytokines were differently affected by the absence of the canonical NF- $\mathrm{B}$ pathway in IECs. Thus, while wild-type and IKK $\beta^{\Delta \mathrm{IEC}}$ mice expressed similar levels of serum IL-4 and IL-5, IKK $\beta^{\Delta \mathrm{IEC}}$ mice exhibited reduced levels of IL-9 and IL-13 (Figure 2C). Serum IL-10 and IL-17 levels were also lower in IKK $\beta^{\Delta \mathrm{IEC}}$ mice (Figure $2 \mathrm{C}$ ).

\section{IKK $\beta$ Mice Have Fewer Eosinophils in the Gut}

Development of allergic responses requires induction of allergenspecific IgE and subsequent activation of mast cells, basophils, and eosinophils (17). Analysis of serum chemokines after oral allergen challenge revealed that the levels of eotaxin-1 (or CCL11), a chemokine that selectively recruits eosinophils, were significantly reduced in IKK $\beta^{\triangle I E C}$ mice (Figure 3A). These mice also 


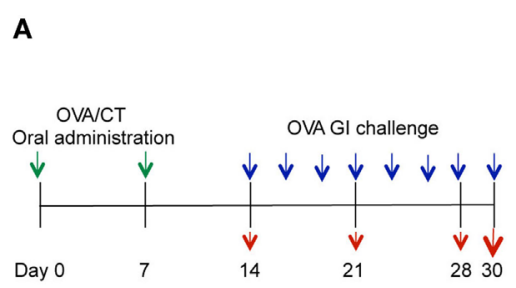

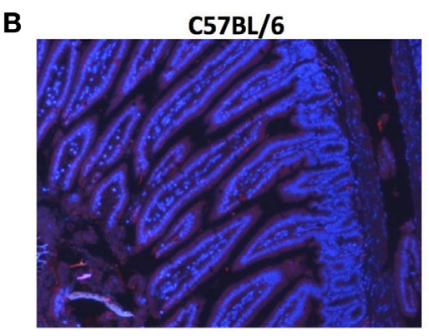

D

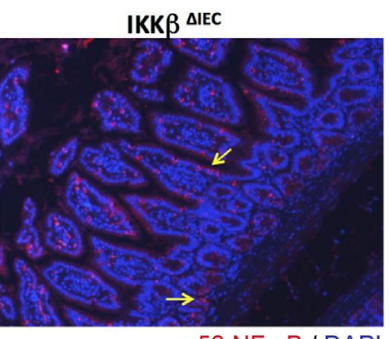

p52 NF-kB / DAPI

C

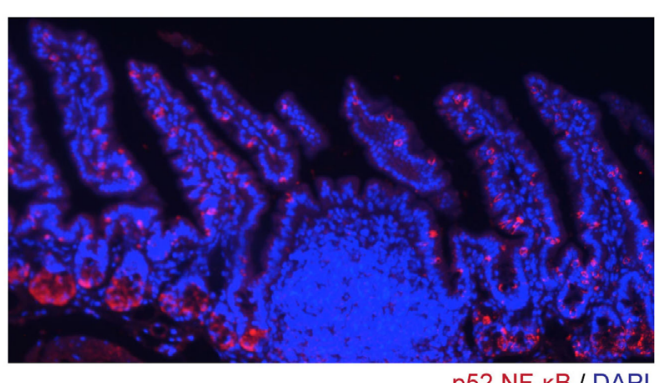

p52 NF-kB / DAPI

E

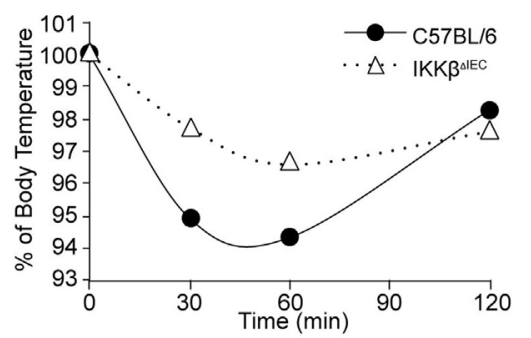

$\mathbf{F}$

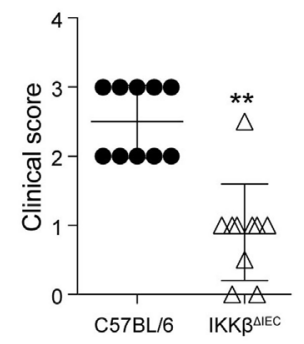

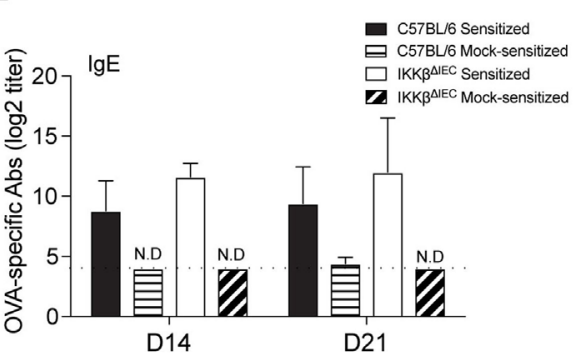

G

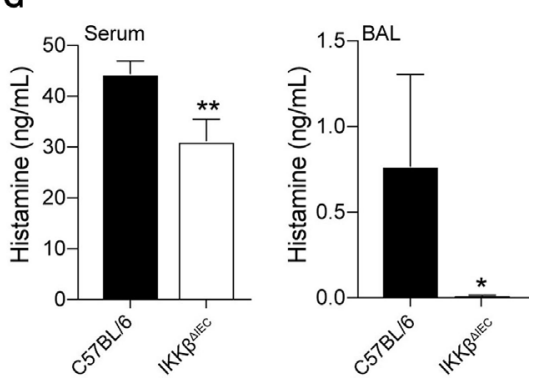

FIGURE 1 | Mice with selective IKK $\beta$-deficiency in intestinal epithelial cells have lower clinical signs of allergy after oral allergen challenge. (A) Experimental scheme. Wild-type C57BL/6 and IKK $\beta^{\Delta \mathrm{EC}}$ mice were orally sensitized by ovalbumin (OVA) allergen and cholera toxin (CT) as adjuvant (green arrows), and then orally challenged with OVA (blue arrows). Serum or lung tissues were collected at days 14, 21, 28, and 30 to analyze antibodies responses or clinical signs of allergy (red arrows). (B) Expression of the non-canonical NF- $\kappa B$ pathways in the intestine of naïve wild-type C57BL/6 and IKK $\beta^{\Delta I E C}$ mice and (C) expression of the non-canonical NF-kB pathways in intestinal villi, crypts, and Peyer's patches of IKK $\beta^{\Delta E C}$ mice. Sections of small intestinal tissues were stained with an anti-p52 NF-kB antibody and counterstained with DAPI to visualize the nuclei. (D) Allergen-specific serum IgE. Mice were sensitized by oral administration of OVA (1 mg) and CT $(15 \mu \mathrm{g})$. Serum samples were collected on days 14 and 21 and OVA-specific IgE titers were determined by enzyme-linked immunosorbent assay (ELISA). The results are expressed as mean $\log _{2}$ titers $\pm 1 \mathrm{SD}$ and are from at least five experiments and five mice/group. (E) Variation (\%) of surface body temperature after oral challenge with OVA (50 mg) on day 30. (F) Clinical scores. Mice were orally challenged with OVA (50 mg) and clinical scores recorded according to the behavior criteria described in Section "Materials and Methods." (G) Histamine levels after nasal allergen challenge with OVA on day 30 . Serum and BAL samples were collected $2 \mathrm{~h}$ after allergen challenge and histamine levels measured by ELISA. Data are expressed as mean \pm SD. ${ }^{*} p<0.05 ;{ }^{* *} p<0.01$.

showed significantly lower levels of inflammatory chemokines (e.g., RANTES, MIP-1a, MCP-1, and KC) (Figure 3A). To further establish that the lower serum CCL11 levels were an indication of impaired eosinophil recruitment in IKK $\beta^{\Delta I E C}$ mice, we analyzed expression of transcripts for eotaxins ( $\mathrm{Ccl11}$ and $\mathrm{Ccl} 24$ ) and other Th2-promoting cytokines (Il-25 and Tslp) in small intestinal tissues collected after the allergen challenges. Wild-type and IKK $\beta^{\triangle I E C}$ mice showed no difference in the levels of $I l-25$ and Tslp mRNA. On the other hand, the mRNA levels of the eosinophil chemoattractant $C c l 11$ and $C c l 24$ were lower in the small intestine of IKK $\beta^{\triangle \mathrm{IEC}}$ than in wild-type mice (Figure 3B). Histological analysis of small intestinal sections stained with an anti-Siglec-F antibody showed the presence of eosinophils in the gut of control wild-type and IKK $\beta^{\Delta I E C}$ mice, and there was no significant difference in the number of eosinophils in these mice at the steady state (not shown). Conversely, oral allergen challenge increased the number of eosinophils in the small intestine of wild-type mice, but not in IKK $\beta^{\triangle \mathrm{IEC}}$ mice (Figure 3C). Consistent with histology, mRNAs levels of eosinophil growth factor (Il-5), eosinophil peroxidase $(E p x)$ were both lower in small intestinal tissues of IKK $\beta^{\Delta I E C}$ than wild-type mice following oral allergen challenge (Figure 3D).

\section{Intrinsic Signals in Epithelial Cells Impair Eotaxin Responses in the Gut of IKK $\beta^{\Delta \mathrm{IEC}}$ Mice}

The altered eotaxin responses in the gut of IKK $\beta^{\Delta \mathrm{IEC}}$ mice could result from endogenous factors due to lack of IKK $\beta$ signaling or exogenous factor via the gut microbiota. We have previously 

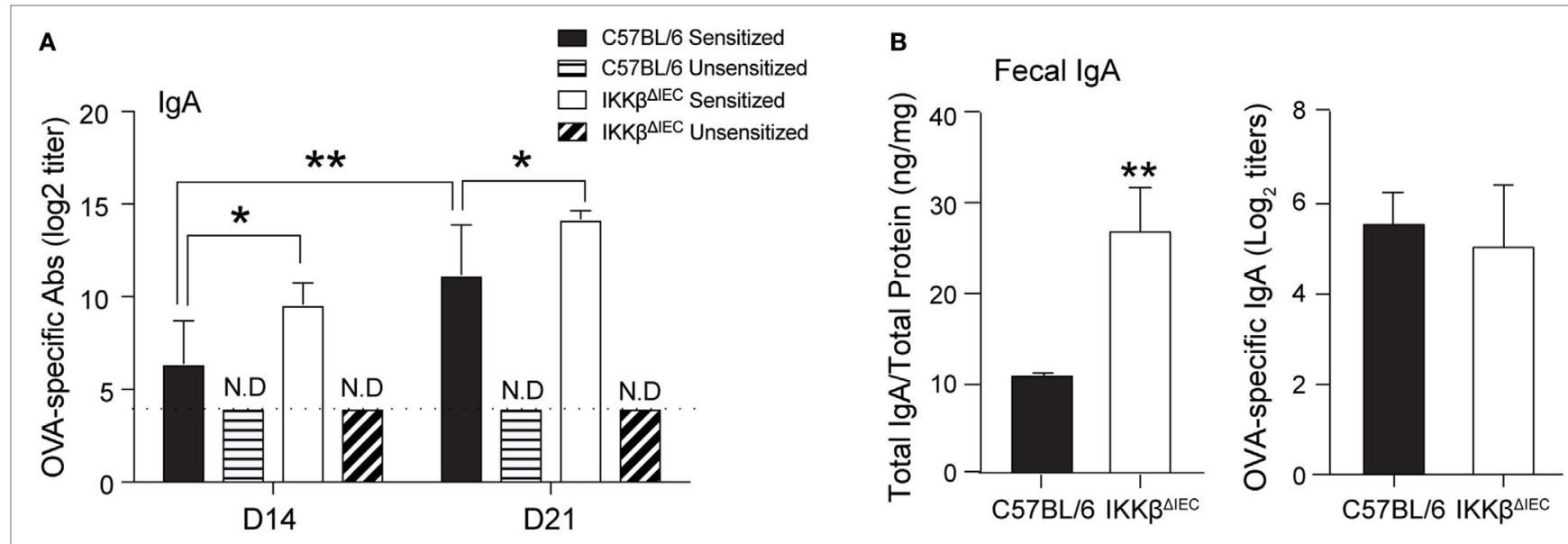

C
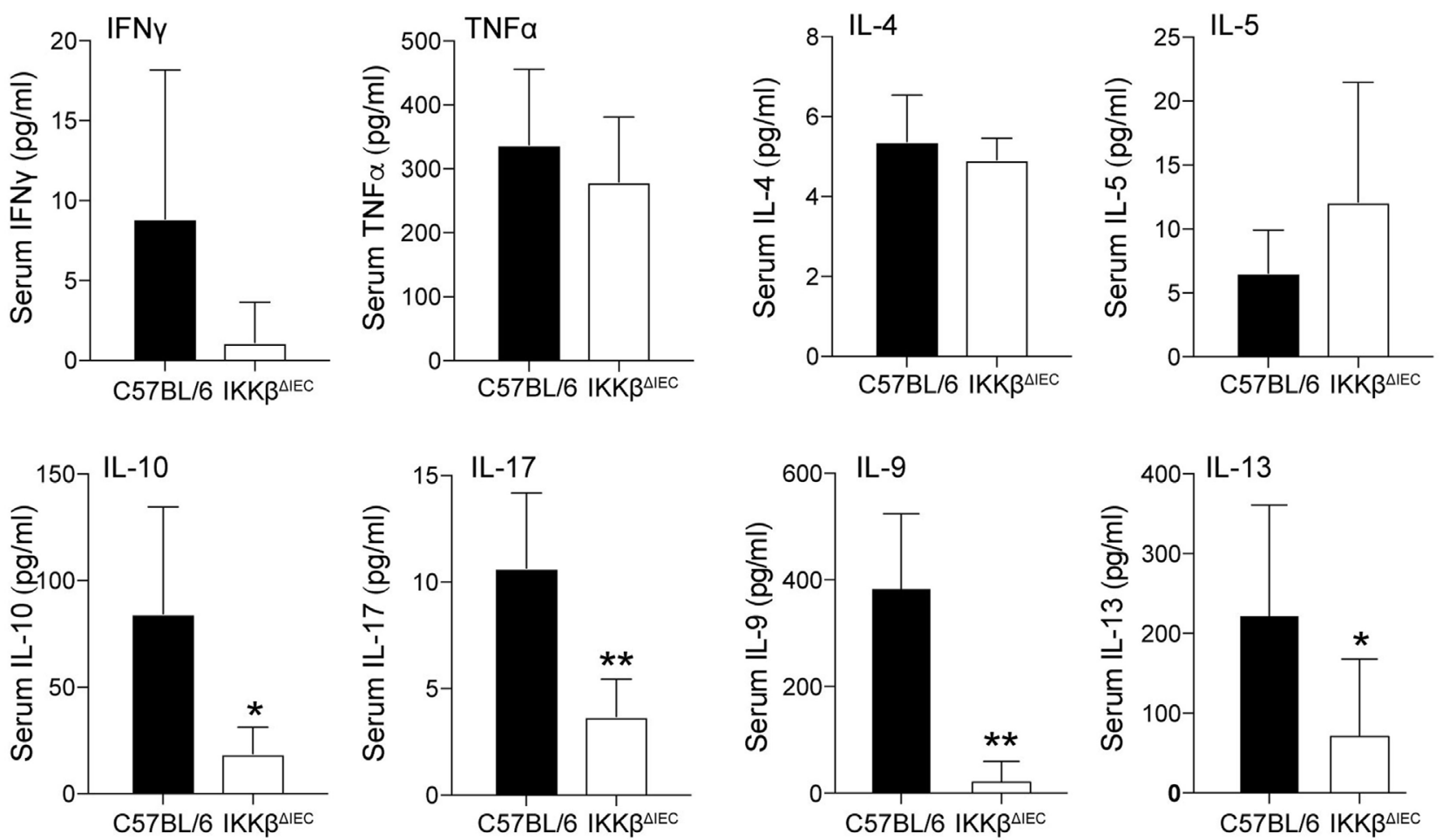

FIGURE 2 | Allergen-specific secretory IgA (SlgA) and serum cytokine responses of IKK $\beta^{\Delta E C}$ mice after oral sensitization and oral allergen challenge. (A) Allergenspecific serum IgA. (B) Total and allergen-specific SlgA in fecal extracts. Mice were sensitized by oral administration of ovalbumin (OVA) (1 mg) and cholera toxin $(15 \mu \mathrm{g})$. Serum were collected on days 14 and 21 , and fecal samples were collected on day 30 . Total and OVA-specific IgA were assessed by enzyme-linked immunosorbent assay. (C) Serum cytokines. Serum samples were collected $2 \mathrm{~h}$ after allergen challenge on day 30, and the concentrations of cytokines were evaluated by a multiplex assay. Data are expressed as mean \pm SD. ${ }^{*} p<0.05 ;{ }^{* *} p<0.01$ and are from at least five experiments and five mice/group.

shown that IKK $\beta^{\triangle \mathrm{IEC}}$ mice display a gut microbiota dysbiosis that is further enhanced after oral administration of CT (13). Linear discriminant analysis (LDA) of commensal bacteria at the family (Figure 4A) and genus (Figure 4B) levels clearly identified bacteria associated with the presence of a functional or non-functional IKK $\beta$ in epithelial cells. Since the presence of butyrate-producing bacteria is often associated with protection against the development of allergic responses (18-21), we also analyzed the profile of metabolites present in the small and large intestines of wild-type and IKK $\beta^{\triangle \mathrm{IEC}}$ mice (Figures $4 \mathrm{C}-\mathbf{G}$ ). Asparagine and threonine levels were significantly reduced in the small intestine of IKK $\beta^{\Delta \mathrm{IEC}}$ mice. Further, the large intestine of these mice contained lower levels of butyrate, tryptophan, and tyrosine while propionate and succinate levels were increased. We also investigated whether these metabolites or other molecules in the fecal contents of wild-type and IKK $\beta^{\triangle I E C}$ mice differentially affected eotaxin expression. We found that addition of bacteria-free fecal material extracts inhibits CCL11 mRNA expression by murine (CMT93) 

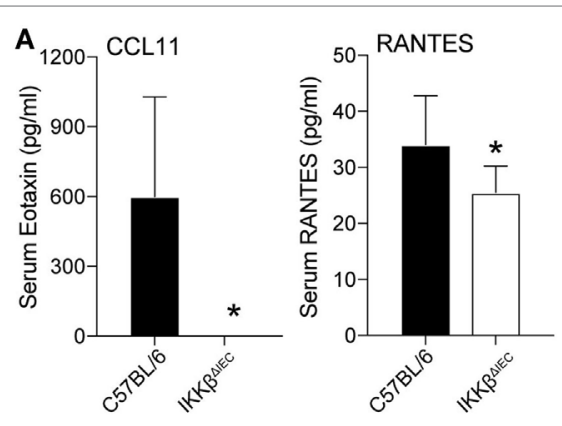

B
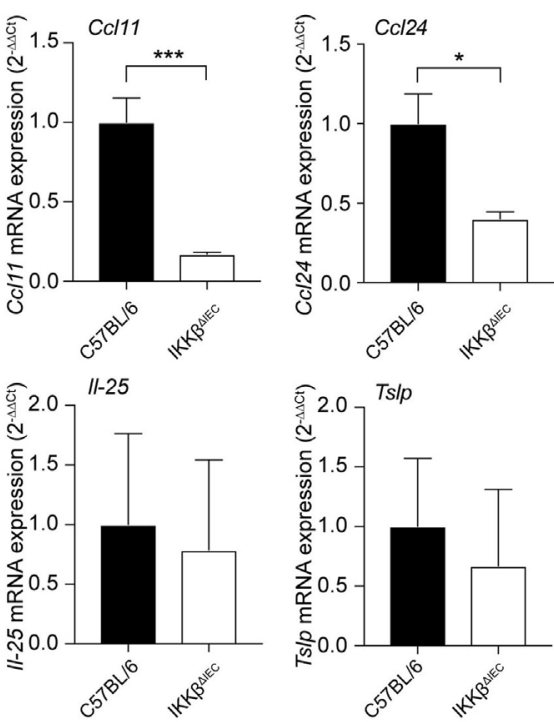
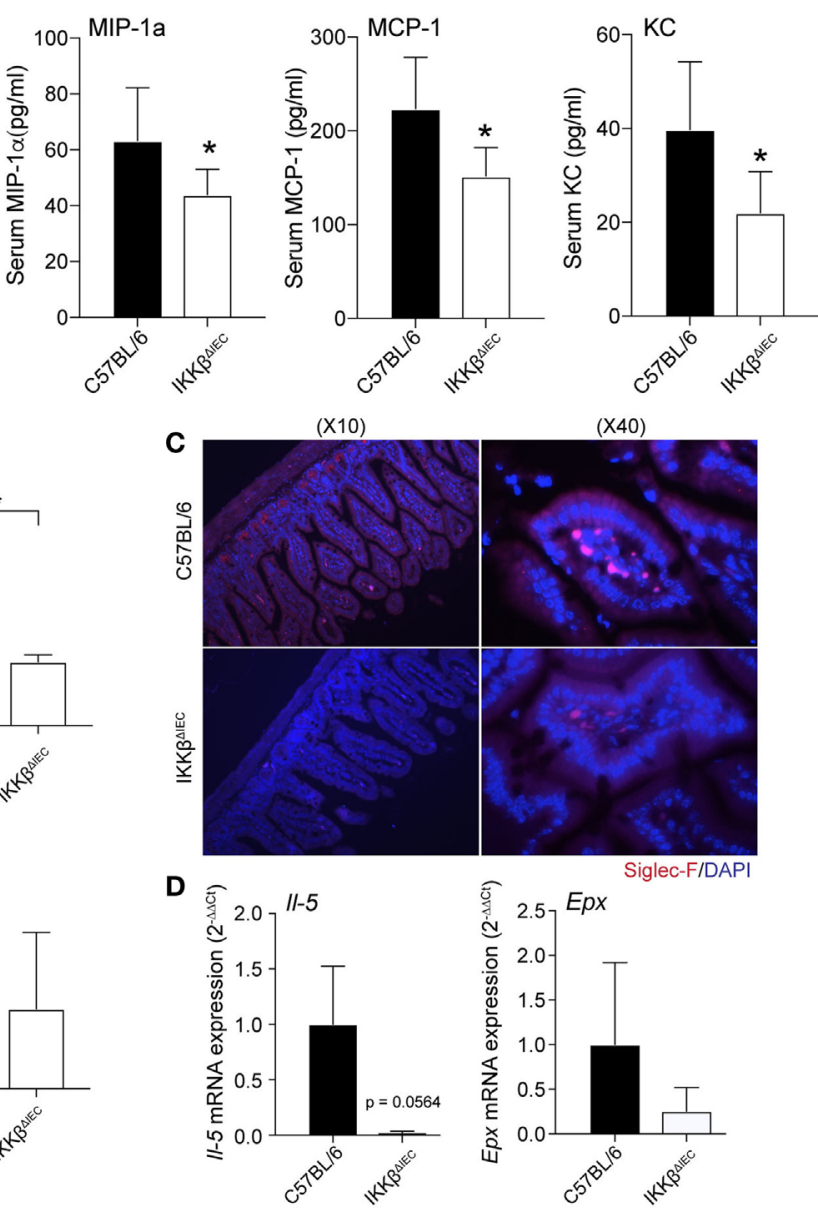

FIGURE 3 | Serum chemokines and gut eosinophil levels in IKK $\beta^{\Delta I E C}$ mice following oral sensitization and oral allergen challenge. (A) Serum chemokines. Serum samples were collected $2 \mathrm{~h}$ after allergen challenge on day 30 and the concentrations of chemokines were evaluated by multiplex assay. Data are expressed as mean $\pm \mathrm{SD} .{ }^{\star} p<0.05 ;{ }^{\star *} p<0.01$ and are from at least five experiments and five mice/group. (B-D) Analysis of small intestinal tissues collected on day 30 and $2 \mathrm{~h}$ after allergen challenge of wild-type and IKK $\beta^{\Delta I E C}$ mice. (B) Eotaxin-1 (Cc/11), eotaxin-3 (Ccl24), il-25, and Ts/p mRNA levels. (C) Eosinophils in small intestine. Thin sections of small intestinal tissues were stained with an anti-Siglec-F antibody and counterstained with DAPI to visualize nuclei. (D) $/ /-5$ and eosinophil peroxide (Epx) mRNA levels. The mRNA data are expressed as mean $\pm \mathrm{SD}$. ${ }^{*} p<0.05$; ${ }^{* *} p<0.01$, and are from at least five experiments and five mice/group.

and human (HT-29) intestinal epithelial cell lines, regardless of the wild-type or IKK $\beta^{\Delta \mathrm{IEC}}$ mouse origin of the fecal materials (Figures 4H,I). Thus, neither the nature of the bacteria nor the metabolites present in the gut of IKK $\beta^{\triangle \mathrm{IEC}}$ mice could explain the altered CCL11 responses.

We next tested if IECs could represent a major source of eotaxin in the gut and whether inhibition or lack of IKK $\beta$ signaling could be sufficient to impair CCL11 production. For this purpose, we used human HT-29 epithelial cells and blocked NF- $\mathrm{B}$ signaling by using sulfasalazine, a pharmacological inhibitor of the canonical NF- $\mathrm{KB}$ pathway. Addition of sulfasalazine to cultures of epithelial cells significantly reduced CCL11 mRNA levels (Figure 5A). This treatment did not affect all cytokine mRNA responses since $I L-1 \beta$, but not $T N F \alpha$ mRNA were downregulated (Figure 5A). We also found that HT-29 epithelial cells cultured in the presence of sulfasalazine have significantly lower CCL11 mRNA responses to exposure to
CT (Figure 5B). To further confirm that IECs were the source of impaired eotaxin responses in the gut of IKK $\beta^{\Delta \mathrm{IEC}}$ mice, we developed organoid cultures from intestinal crypt cells of wild-type and of IKK $\beta^{\Delta I E C}$ mice (Figure 5C). As depicted in Figure 5C, cells from IKK $\beta^{\Delta I E C}$ mice formed organoid that resembled those of control mice. Furthermore, these organoids were functional as they accumulated fluid after stimulation with CT (Figure 5C). It is worth noting that organoids of IKK $\beta^{\Delta \mathrm{IEC}}$ mice seemed less inflated after stimulation with CT than those of control wild-type mice, and this was consistent with the reduced intestinal fluid accumulation seen after these mice were given CT by oral gavage (not shown). Finally, immunofluorescence analysis of organoids stained with an anti-CCL11 antibody demonstrated that although organoids of IKK $\beta^{\triangle \mathrm{IEC}}$ mice expressed CCL11, their levels were significantly lower than those detected in organoids derived from control wild-type mice (Figure 5D). 

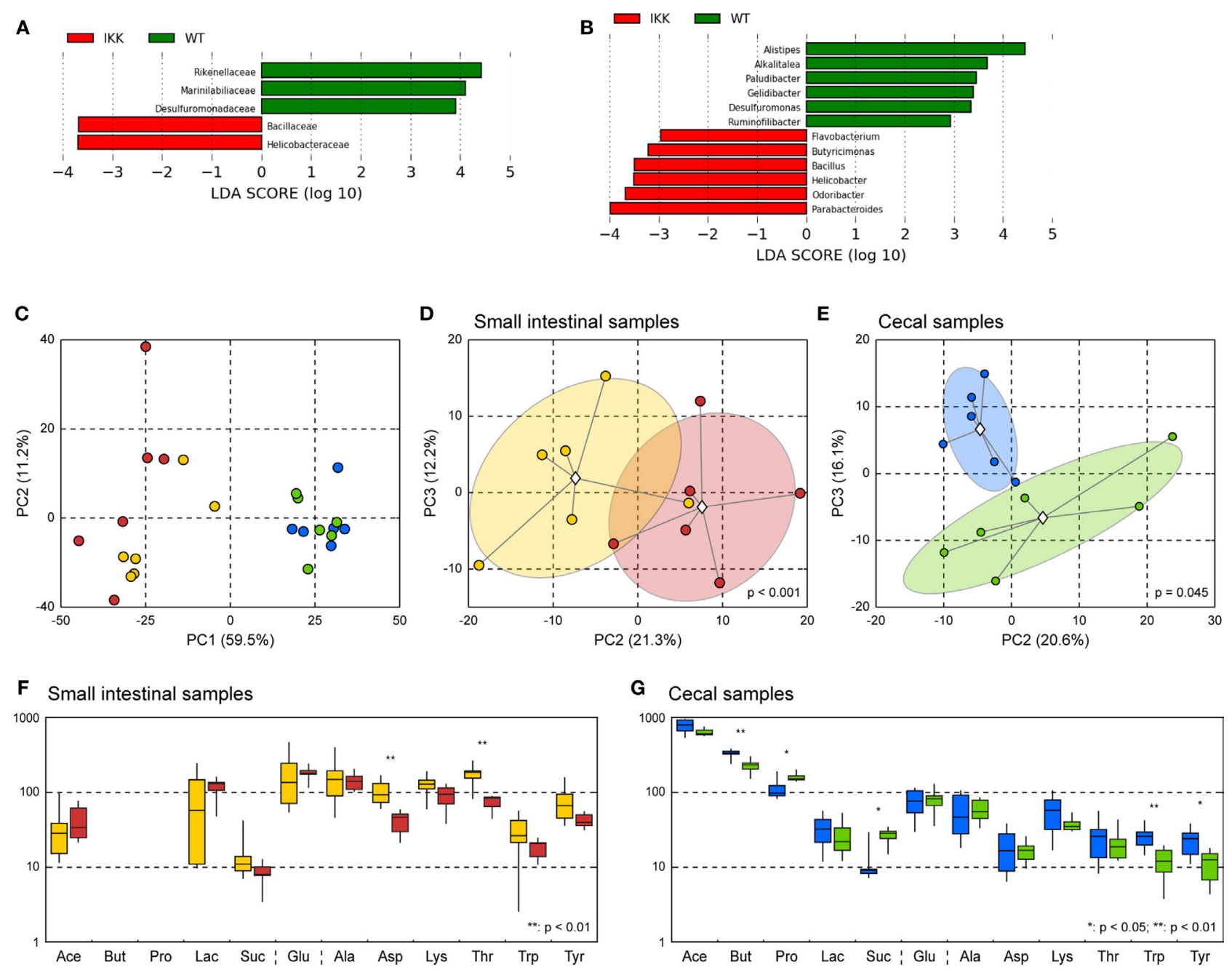

G Cecal samples
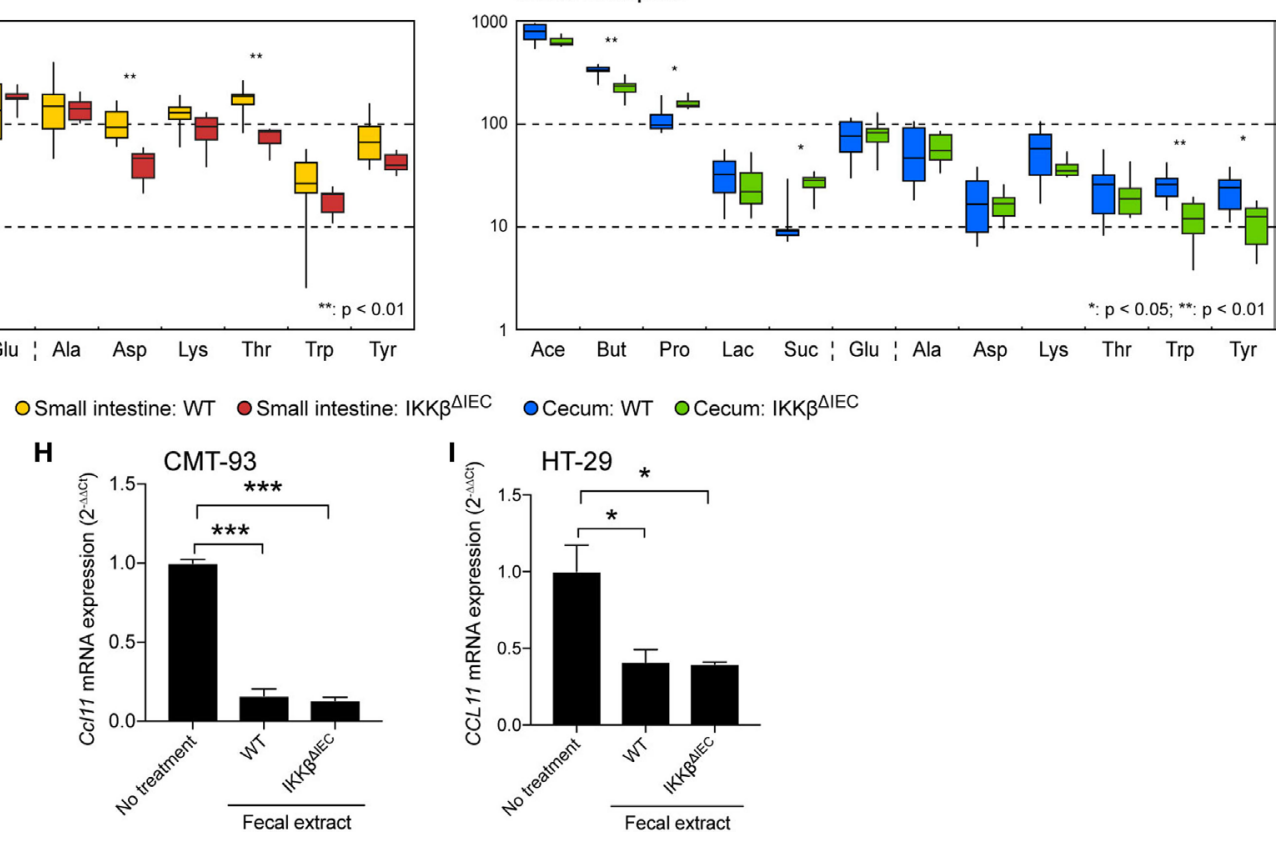

FIGURE 4 | Commensal bacteria and metabolite profiles are altered in the gut of naïve IKK $\beta^{\Delta I E C}$ mice. (A,B) Linear discriminant analysis (LDA) of the abundances of commensal gut bacteria. Freshly emitted fecal pellet were normalized by weight and microbial composition determined by $16 S$ RNA analysis. (A) LDA scores at the family level. (B) LDA scores at the genus level. (C-G) Metabolite profiling. (C-E) Principal component analyses (PCA) of metabolite profiles. Different groups are denoted by colors as shown in the legend. Group clouds represent areas of three SEs around the group centroid (diamond). Percent of total variance captured by each principal component is shown in parentheses. $P$ values indicate the statistical significance of group separation in the first three components of the PCA space as assessed by permutation analysis of Davies-Bouldin index. (C) Small and large intestines; (D) small intestine; (E) large intestine. (F) Distribution of concentrations of major metabolites in the small intestine. (G) Distribution of concentrations of major metabolites in the large intestine. Boxplot whiskers depict minimum and maximum values for each group. $P$ values were calculated using two-tailed $T$-test, ${ }^{*} p<0.05 ;{ }^{* *} p<0.01$ (five mice/group). Abbreviations: Ace, acetic acid; But, butyric acid; Pro, propionic acid; Lac, lactic acid; Suc, succinic acid; Glu, glucose; Ala, alanine; Asp, aspartic acid; Lys, lysine; Thr, threonine; Trp, tryptophan; Tyr, tyrosine. Note that there were no discernable nuclear magnetic resonance peaks for butyric and propionic acids in any small intestinal samples. (H,I) CCL11 mRNA expression of in murine CMT-93 (H) and human HT-29 intestinal epithelial cells (I). Cells were cultured for $12 \mathrm{~h}$ in the presence of bacterial-free fecal extracts from wild-type and IKK $\beta^{\Delta \mathrm{EEC}}$ mice. ${ }^{\star} p<0.05 ;{ }^{\star \star} p<0.01 ;{ }^{\star \star \star} p<0.001$ compared to no treatment controls. 


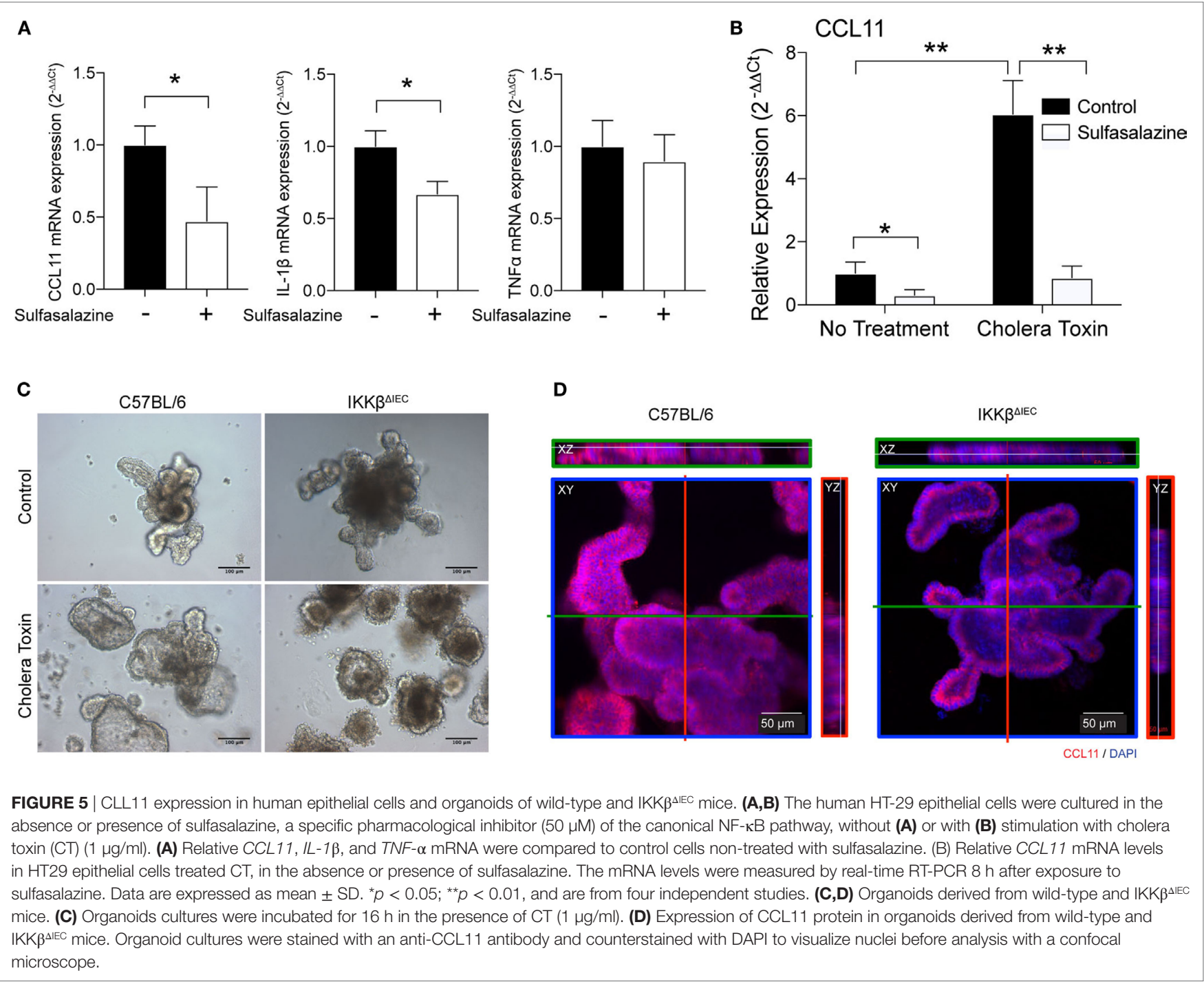

\section{Oral Administration of CCL11 Protein Restores Clinical Signs of Allergy in IKK $\beta^{\Delta I E C}$ Mice}

Most studies addressed the regulatory effect of cytokines in vivo after parenteral injection. However, cytokines were also administered orally to test their role/effect in a variety of experimental systems (22-26). In our own previous studies, oral delivery of IL-12 failed to result in significant levels of serum IL-12 (27). However, this treatment was able to promote IgG2a/c and suppress IgE antibody responses in mice orally immunized with CT as adjuvant (27), indicating that cytokine can be administered orally to assess their effect in mucosal tissues and to a lesser extent in the bloodstream. Thus, to confirm the central role of intestinal epithelial cell-derived CCL11 in the effector phase of allergic response, orally sensitized IKK $\beta^{\Delta \mathrm{IEC}}$ mice were orally administered recombinant CCL11 protein at the time of oral allergen challenges (Figure 6A). Oral treatment with CCL11 did not induce major changes in OVA-specific antibody responses (Figure 6B). Thus, it only affected OVA-specific IgG2b, which were downregulated after ingestion of CCL11 recombinant protein and reached similar levels than in control wild-type mice (Figure 6B). Interestingly, allergic response to oral allergen challenge were restored in IKK $\beta^{\triangle \mathrm{IEC}}$ mice after treatment with CCL11. More specifically, IKK $\beta^{\triangle \mathrm{IEC}}$ mice that received CCL11 had serum histamine levels that were closer to those of control wild-type mice after oral allergen challenge (Figure 6C). Furthermore, other clinical signs of allergy including behavior score and body surface temperature were restored to levels similar to wild-type C57BL/6 after ingestion of CCL11 (Figure 6D).

\section{DISCUSSION}

Epithelial cells sense intestinal microbes and produce initial innate signals that regulate host response to microbes and food products. It is now well established that health is associated with balanced gut microbiome, while dysbiosis can lead to a variety of diseases including allergy. Here, we examined the role played by IECs in the effector phase of allergic responses following 


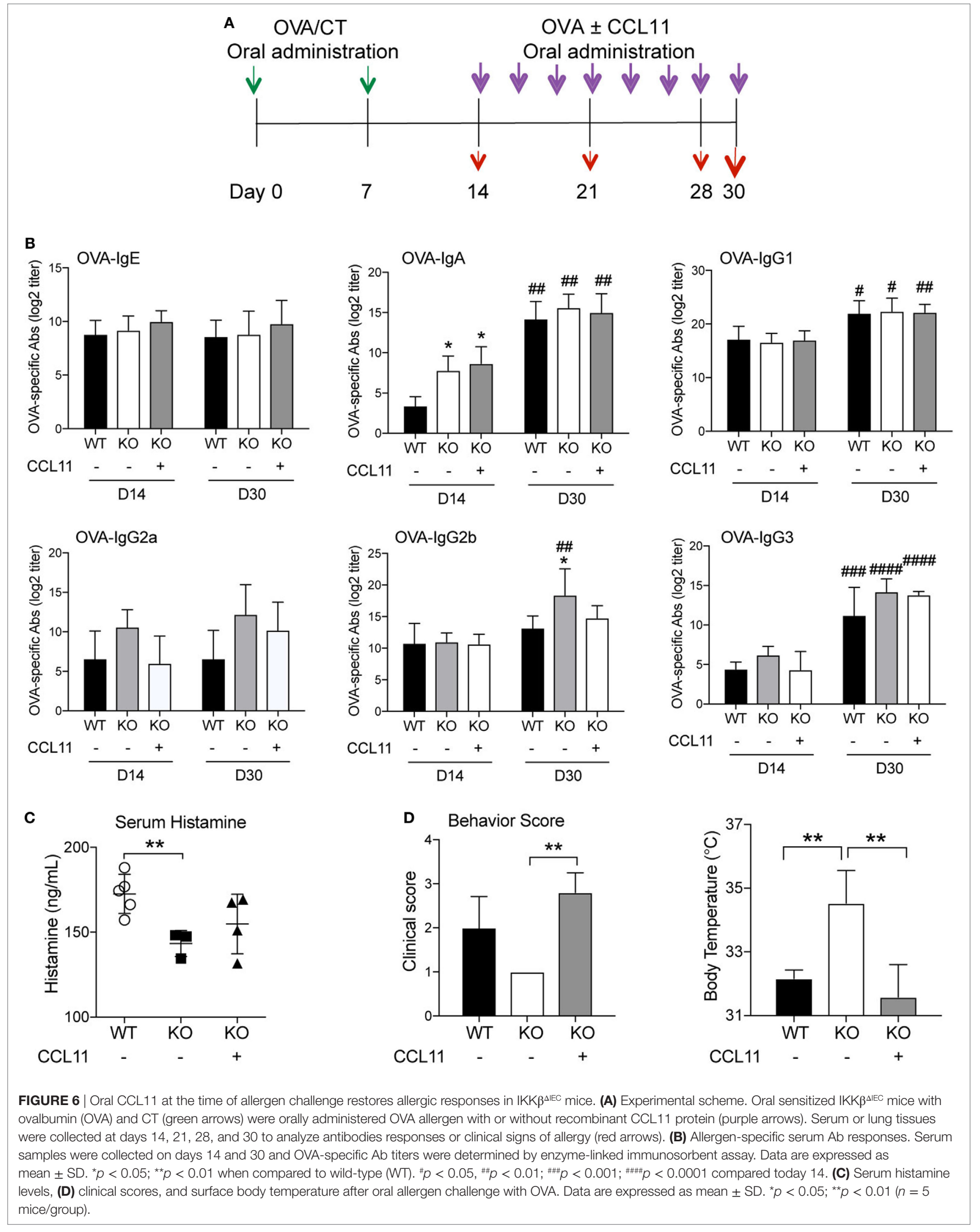


ingestion of allergen. The data summarized herein show that the canonical NF- $\mathrm{KB}$ signaling in IECs has no significant effect on allergic sensitization and the development of allergen-specific IgE responses. However, it regulates eotaxin production by IECs and thus, the recruitment of eosophils in the gut during the effector phase of allergic responses and the severity of clinical manifestations of disease.

In response to microbial stimuli or parasite infection, IECs produce cytokines, such as TLSP, which trigger a cascade of events leading to production of IgE. Recent evidence suggests that intrinsic signaling pathways in these cells could regulate production of other immunoglobulin isotypes. In this regard, our previous studies have shown that impaired canonical $\mathrm{NF}-\mathrm{\kappa B}$ signaling in IECs creates a cytokine microenvironment that facilitates production of $\operatorname{IgA}$, and that oral sensitization of IKK $\beta^{\triangle I E C}$ mice results in high levels of allergen-specific IgA in the bloodstream (13). The fact that clinical signs of allergy following nasal allergen challenge were less severe in orally sensitized IKK $\beta^{\triangle I E C}$ mice and that this protection correlated with the levels of allergen-specific IgA in the secretions of the airways demonstrated the following two important points. First, it indicates that IECs can regulate the effector phase of allergic response at a distant mucosal site. It also supports the notion that the presence of allergen-specific SIgA at a mucosal site of allergen challenge can affect the effector phase of allergic response and limit the severity of disease. Here, we showed that orally sensitized IKK $\beta^{\Delta \mathrm{IEC}}$ mice are protected from the development of severe signs of allergy via mechanisms independent of IgA. As depicted in Figure 2, the titers of allergen-specific SIgA measured in fecal extracts were not higher than those seen in control wild-type mice. This finding confirms that allergen-specific serum and SIgA are differentially regulated. It also suggests that the higher levels of total IgA in fecal extracts of IKK $\beta^{\triangle \mathrm{IEC}}$ mice could result from increase secretion of IgA by peritoneal B1 cells in response to the inflammatory microenvironment.

Both the p65-mediated canonical and the p52-mediated noncanonical NF- $\kappa \mathrm{B}$ pathways of neutrophils were reported to positively correlate with allergic symptom scores in human patients (28). Our findings indicate that the sensitization phase and $\mathrm{IgE}$ responses were not impaired by activation of p52 NF- $\mathrm{\kappa B}$ in the absence of canonical NF- $\mathrm{KB}$ pathways in IECs and this was consistent with the fact that WT and IKK $\beta^{\Delta \mathrm{IEC}}$ mice displayed similar levels of Tslp and Il-25 mRNA in the gut after oral allergen challenge. A previous report showed that IKK $\beta^{\Delta I E C}$ mice are unable to produce TSLP and mount the mucosal Th2 responses required to eradicate infection with the gut-dwelling parasite Trichuris (29). Our data are consistent with the previous report that CT induced TSLP production by IECs (10) and demonstrate that TSLP can be induced even in the absence canonical $\mathrm{NF} \kappa \mathrm{B}$ signaling in IECs.

While the sensitization phase was not affected in our studies, a major finding from this work is the evidence that IECs can reduce allergic responses in the gut by limiting the recruitment of eosinophils. The Th 2 cytokine IL-5 is crucial for the expansion and survival of eosinophils (30), but these cells are recruited to different sites by the chemokine CCL11 (eotaxin-1). Parenteral injection of cytokine is often the preferred route of delivery to address their regulatory effects of cytokines. However, this approach leads to high amounts of cytokines being present in the bloodstream and thus, may not allow to assess host responses to cytokines produced in mucosal tissues. We and other have previously shown that orally delivered cytokines can retain their biological activities (22-26). More importantly, we previously showed that even in the absence of significant levels of IL-12 in serum after oral administration, this treatment could promote IgG2a/c and suppress IgE antibody responses in mice orally immunized with CT as adjuvant (27). In the present study, oral administration of CCL11 helped established that the impaired/ reduced production of this chemokine in the gut was the leading factor for reduced allergic responses despite high levels of allergen-specific IgE in the bloodstream.

Mast cells and basophils are major contributors to anaphylaxis. Eosinophils are other effector cells for allergic responses. Allergic responses from mast cell and basophil are IgE-dependent due to their expression of high-affinity $\operatorname{IgE}$ receptor (FceRI) and develop during the early stage of exposure to allergen. Response from eosinophils develops slower and is more steady than that of those cells. Our data shows no difference in $\operatorname{IgE}$ level (Figure 1D), but differences in allergic behavior between WT and IKK $\beta$-deficient mice. Thus, high clinical behavior were measured after $30 \mathrm{~min}$ in WT mice, while IKK $\beta$-deficient mice only showed mild signs during the observation period. The gut microbiota is believed to play a significant role in the regulation of allergic responses and the presence of butyrate-producing bacteria is often associated with protection again the development of allergic responses (18-21). Our data show that the dysbiosis in IKK $\beta^{\triangle \mathrm{IEC}}$ mice was associated with reduced butyrate levels and thus suggest that lack of allergic symptoms in these mice was not due a protective effect of the microbiota or their products.

Intestinal epithelial cells were shown to produce CCL11 (31), and we now report that this process is regulated by the canonical NF- $\kappa \mathrm{B}$ pathway in IECs. Our finding is consistent with the presence of an NF- $\kappa \mathrm{B}$ binding site on the CCL11 promoter (32), and the previous report that inflammatory monocytes $\left(\mathrm{F} 4 / 80^{+} \mathrm{CD} 11 \mathrm{~b}^{+} \mathrm{Ly}^{\mathrm{hi}}\right)$ of mice lacking the canonical NF- $\kappa \mathrm{B}$ in myeloid cells (RelA/p65 ${ }^{\Delta \text { mye }}$ mice) have reduced expression of CCL11 (33). It is worth indicating that in a model of cutaneous and lung melanoma tumors, macrophages lacking IKK $\beta$ were reported to have enhanced production of CCL11 (34). Thus, while collectively these studies demonstrate a link between the canonical NF- $\mathrm{KB}$ pathway and CCL11, the suppressive or stimulatory effect of this signaling pathway on the production of this chemokine may differ depending of the cells and stimuli involved. Another point to consider is whether or not the impaired recruitment of eosinophils in the gut of IKK $\beta^{\triangle I E C}$ mice has implication on other immune responses beside the lower magnitude of allergic responses. In this regard, eosinophils were recently shown to promote immunoglobulin class switch recombination and production of IgA by providing active TGF $\beta$ (35). Thus, the lower levels of allergen-specific mucosal IgA in the gut of IKK $\beta^{\triangle I E C}$ mice could be related to the impaired production of CCL1 1 by IECs and subsequent reduced number of eosinophils in gut tissues. 
Intestinal epithelial cells form the barrier that regulates the entry of exogenous pathogens and allergens. They have been more recently recognized as important members of the network of innate immune cells, which regulate the signature of the adaptive immune response through cytokines and chemokines they produce. Here, we show a new role of IECs in the regulation of the effector phase of allergic responses in the GI tract through their control of eotaxin production. This new knowledge sets the stage for future anti-allergy therapies targeting IKK $\beta$ signaling in IECs or oral delivery of anti-CCL11.

\section{MATERIALS AND METHODS}

\section{Mice}

Control wild-type C57BL/6 mice were obtained from the Jackson Laboratory (Bar Harbor, ME, USA). C57BL/6 mice in which IKK $\beta$-dependent NF- $\kappa \mathrm{B}$ signaling was selectively eliminated in the IECs $\left(\mathrm{IKK} \beta^{\triangle \mathrm{IEC}}\right)$ were generated as previously described $(36,37)$. All animals were maintained under specific pathogen free conditions at The Ohio State University (OSU) animal care facility. Studies were approved by the Institutional Animal Care and Use Committee (IACUC, protocol \#2008A0210) and performed on mice aged 10-12 weeks, in accordance with NIH and OSU IACUC guidelines.

\section{Oral Sensitization and GI Antigen Challenge}

Oral allergic sensitization and oral allergen challenge were performed as depicted in Figure 1A. For oral sensitization, mice were given $1 \mathrm{mg}$ of OVA (grade V, Sigma-Aldrich, St. Louis, MO, USA) and $15 \mu \mathrm{g}$ of CT (List Laboratories, Campbell, CA, USA) in $250 \mu \mathrm{l}$ of phosphate-buffered saline (PBS), by intragastric gavage. Antigen challenge was performed eight times starting on day 14 by intragastric gavage of $50 \mathrm{mg}$ of OVA (grade II, Sigma-Aldrich) in $500 \mu \mathrm{l}$ of PBS.

\section{Assessment of Antigen-Specific IgG and IgA Ab Responses and Total IgA Levels}

Total and OVA-specific Ab responses were measured in sera and fecal material extracts by enzyme-linked immunosorbent assay (ELISA) as previously described $(13,38)$. Briefly, microtiter plates were coated with OVA $(1 \mathrm{mg} / \mathrm{ml})$. For detection of OVA-specific IgG and IgA Abs, serial dilutions of serum or fecal material extract were added to the plates and the binding antibodies were detected with HRP-conjugated antimouse $\gamma$ - or $\alpha$-heavy chain-specific antisera (Southern Biotech Associates Inc., Birmingham, AL, USA). Biotin-conjugated rat anti-mouse IgG1, IgG2a/c, IgG2b, or IgG3 monoclonal Abs and HRP-conjugated streptavidin (BD Bioscience, San Jose, CA, ISA) were used to measure IgG subclass responses. The $\mathrm{Ab}$ titers were determined as the last dilutions of samples that with an absorbance of $>0.1$ above that of control samples from naïve mice.

Total IgA levels were determined by ELISA using extrapolation against IgA standards (38). Freshly emitted fecal pellets from IKK $\beta^{\Delta \mathrm{IEC}}$ and control mice were normalized by dissolution of
$0.1 \mathrm{~g}$ feces in $1 \mathrm{ml}$ of PBS, and the levels of IgA in fecal material extracts were further normalized by the amounts of total protein in each sample.

\section{Total and Antigen-Specific IgE Abs}

Total IgE Ab levels were determined by a BD OptEIA ${ }^{\mathrm{TM}}$ Set Mouse IgE (BD PharMingen) according to instructions from the manufacturer. To prevent interference of IgG in the assay, serial dilutions of immune plasma were first depleted of IgG by overnight incubation in Reacti-Bind ${ }^{\mathrm{TM}}$ Protein G Coated Plates (Pierce, Rockford, IL, USA). In order to detect antigen-specific IgE, the microtiter plates were coated with OVA $(1 \mathrm{mg} / \mathrm{ml})$. Serial dilutions of IgG-depleted plasma were then added and IgE were detected with a biotinylated anti-mouse $\operatorname{IgE} \mathrm{Ab}(\mathrm{BD}$ Biosciences). The IgE titers were determined as the last dilution of samples that achieved an absorbance of $>0.1$ above that of control samples.

\section{Assessment of Surface Body Temperature}

Body temperature was assessed by measuring surface body temperature with the aid of infrared thermometers [Heat spy infrared thermal imaging camera (Wahl, Culver City, CA, USA)].

\section{Clinical Signs of Allergy}

Clinical behavior of allergy were evaluated for $30 \mathrm{~min}$ after oral allergen challenge by two independent researchers and assessed according to previously established guidelines (39). Briefly, the behavior associated with the following $0-5$ scores are: $0=$ no signs; 1 = scratching and rubbing around nose and head; $2=$ reduced activity, self-isolation, and/or decreased activity with increased respiratory rate; $3=$ motionless period lasting for more than $1 \mathrm{~min} ; 4=$ no activity against stimuli and/or convulsion; and $5=$ death.

\section{Collection of Bronchoalveolar Lavage Fluids (BALF)}

Bronchoalveolar lavage fluids were collected via cannulation of exposed trachea, by infusion of $1 \mathrm{ml}$ of sterile PBS through a 22-Gauge catheter into the lungs, followed by aspiration of the fluid into a syringe. BALF samples were centrifuged $(5 \mathrm{~min}$ at $1,500 \mathrm{rpm}$ ) and supernatants were collected and stored at $-80^{\circ} \mathrm{C}$ and analyzed as previously reported (13).

\section{Assessment of Histamine Levels}

Serum histamine levels were assessed in samples collected $2 \mathrm{~h}$ after the last oral allergen challenge using a histamine ELISA kit (My Biosource, San Diego, CA, USA) and according to manufacturer's instruction.

\section{Measure of Cytokines and Chemokines}

The concentration of cytokines and chemokines in biological fluids (i.e., serum or BALF) and culture supernatants were evaluated by multiplex assay using the Mouse Cytokine 23-plex Panel (Bio-Rad, Hercules, CA, USA) and according to manufacturer's instruction. 


\section{Histology}

Immunohistochemistry was performed on thin $(5 \mu \mathrm{m})$ sections of formalin-fixed and paraffin-embedded tissues. Intestines were extensively washed with cold PBS before fixation. Tissue sections were stained with Periodic Acid-Shiff. For immunohistochemistry, tissues were stained with the following antibodies (Santa Cruz Biotechnology, Dallas, TX, USA): anti-p100/p52 (dilution 1:100); anti-Siglec-F (dilution 1:100), and anti-CCL11 (Abcam, Cambridge, MA, USA, dilution 1:50) and secondary fluorescent Abs. Nuclei were counterstained with DAPI.

\section{Intestinal Epithelial Cell Line}

The human intestinal epithelial cell line HT-29 and the murine intestinal epithelial cell line CMT93 were was cultured in DMEM (Gibco, Rockville, MD, USA) containing 10\% fetal calf serum. To address the effect of NF- $\kappa$ B inhibition on steady-state or cytokine responses to CT, HT-29 cells were incubated in the presence of the specific NF- $\mathrm{B}$ inhibitor sulfasalazine (Sigma-Adrich, St. Louis, MO, USA).

\section{Real-Time PCR}

Tissues were collected, snap frozen, and reduced to powder before adding TRIzol (Invitrogen, Carlsbad, CA, USA). The cDNA was synthesized by using Superscript III (Invitrogen) and real-time PCR was performed as previously described (40) with the aid of primers listed in Table 1. The data were expressed as relative mRNA expression $=2^{-\Delta \Delta \mathrm{Ct}}$ where $\Delta \mathrm{Ct}=\mathrm{Ct}_{\text {unknown }}-\mathrm{Ct}_{\mathrm{HKG}}$, and normalized against two house-keeping genes: $\beta$-actin and

TABLE 1 | List of primers used for real-time RT-PCR.

\begin{tabular}{|c|c|c|c|c|}
\hline Species & Name & & Sequence & Size \\
\hline \multirow[t]{16}{*}{ Mouse } & Hprt1 & $\mathrm{F}$ & GAG GAG TCC TGT TGA TGT TGC CAG & 173 \\
\hline & & $\mathrm{R}$ & GGC TGG CCT ATA GGC TCA TAG TGC & \\
\hline & $\beta$-actin & $\mathrm{F}$ & GCG CAA GTA CTC TGT GTG GA & 162 \\
\hline & & $\mathrm{R}$ & GAA AGG GTG TAA AAC GCA GC & \\
\hline & Ccl11 & $\mathrm{F}$ & TCC TTC ATG ACC TTG TGC AG & 162 \\
\hline & & $\mathrm{R}$ & GGA ATA GAA GCG CTG TGG AG & \\
\hline & Ccl24 & $\mathrm{F}$ & AGC CTT CTA AAG GGG CCA AG & 140 \\
\hline & & $\mathrm{R}$ & CCC CAA AGC AGC CTG GTA AA & \\
\hline & $11-25$ & $\mathrm{~F}$ & GGA TGG CCC CCT CAA CA & 66 \\
\hline & & $\mathrm{R}$ & CGA TTC AAG TCC CTG TCC AAC T & \\
\hline & $T s / p$ & $\mathrm{~F}$ & GCT TGT CTC CTG AAA ATC GAG TAT & 83 \\
\hline & & $\mathrm{R}$ & CTC CGG GCA AAT GTT TTG TC & \\
\hline & $11-5$ & $\mathrm{~F}$ & CAG TGT GTA GCC AAG GGT GAC & 166 \\
\hline & & $\mathrm{R}$ & TGA AGT TAG ATA GGA GCA GGA AGC & \\
\hline & Epx & $\mathrm{F}$ & TCA GAT TGT GCG CTT CCC CAG C & 164 \\
\hline & & $\mathrm{R}$ & GGG CAC AGG TCT TCT CAC AGT CCA & \\
\hline \multirow[t]{8}{*}{ Human } & $\beta-A C T I N$ & $\mathrm{~F}$ & TGG GCA TGG GTC AGA AGG AT & 84 \\
\hline & & $\mathrm{R}$ & GCT CGA TGG GGT ACT TCA GG & \\
\hline & CCL11 & $\mathrm{F}$ & GGG CCA GCT TCT GTC CCA AC & 225 \\
\hline & & $\mathrm{R}$ & TTA TGG CTT TGG AGT TGG AGA ПT & \\
\hline & $I L-1 \beta$ & $\mathrm{F}$ & AAA TAC CTG TGG CCT TGG GC & 101 \\
\hline & & $R$ & गाT GGG ATC TAC ACT CTC CAG CT & \\
\hline & $T N F \alpha$ & $\mathrm{F}$ & CCC AGG GAC CTC TCT CTA ATC A & 104 \\
\hline & & $\mathrm{R}$ & GCT TGA GGG TाT GCT ACA ACA TG & \\
\hline
\end{tabular}

hypoxanthine-guanine phosphoribosyl-transferase. The list and sequence of primers are provided in Table 1.

\section{Epithelial Cell Organoid Cultures}

Intestinal organoids of wild-type C57BL/6 and IKK $\beta^{\Delta \mathrm{IEC}}$ mice were generated by culture of crypts of small intestine in Intesti Cult ${ }^{\mathrm{TM}}$ growth media (STEMCELL technologies, Cambridge, MA, USA) as previously reported $(41,42)$. Briefly, intestinal crypts were isolated from small intestine of wild-type or IKK $\beta^{\Delta \mathrm{IEC}}$ mice by incubation with $2 \mathrm{mM}$ of EDTA for $30 \mathrm{~min}$ at $4^{\circ} \mathrm{C}$, mixed with $50 \mu \mathrm{l}$ of Matrigel (BD Bioscience) and placed in prewarmed 24-well culture plates. The numbers of organoids were maintained around 200 per well.

\section{Oral Treatment With Recombinant CCL11}

The oral treatment with a recombinant CCL11 (R\&D Systems, Minneapolis, MN, USA) was performed as previously described with modifications (27). Briefly, groups of sensitized mice were deprived of food for $2 \mathrm{~h}$, followed by intragastric administration of an isotonic bicarbonate solution (8 parts HBSS and 2 parts $7.5 \%$ sodium bicarbonate) to neutralize stomach acidity. Individual mice were gavaged with a $0.1 \mathrm{ml}$ PBS solution ( $\mathrm{pH} 7.2$ ) containing $1 \mu \mathrm{g}$ of recombinant CCL11 and $30 \mathrm{~min}$ later, were gavaged with $50 \mathrm{mg}$ of OVA in $0.5 \mathrm{ml}$ of PBS.

\section{Analysis of Gut Microbiota}

Freshly emitted fecal pellets were collected for all studies. Briefly, freshly emitted fecal pellets samples were collected, normalized weight, snap frozen, and stored at $-80^{\circ} \mathrm{C}$. Samples were collected twice a day from each individual mouse and pooled to minimize potential daily variation of the microbiota. The bacterial tag-encoded FLX amplicon pyrosequencing (Roche, Branford, CT, USA) was used for identification of primary populations of microbes in fecal pellets as previously described (13). Briefly, Bacterial DNA was extracted by conventional methods (Qiagen, Valencia, CA, USA), and 16S rRNA genes were amplified with the modified $16 \mathrm{~S}$ Eubacterial primers $27 \mathrm{~F}$, 5-GAG TTT GAT CNT GGC TCA G-3' and 519R, 5-GTN TTA CNG CGG CKG CTG-3' for amplifying the 500 bp region of $16 \mathrm{~S}$ rRNA genes. The primer sets used for FLX-Titanium amplicon pyrosequencing were designed with adding linker $A$ and 8 base pair barcode sequence at the $5^{\prime}$ end of forward primers as follow: 27 F-A, 5-CCA TCT CAT CCC TGC GTG TCT CCG ACT CAG-barcode-GAG TTT GAT CNT GGC TCA G-3'. The biotin and linker B sequence at the $5^{\prime}$ end of reverse primer 519R-B: 5-Biotin-CCT ATC CCC TGT GTG CCT TGG CAG TCT CAG GTN TTA CNG CGG CKG CTG3'. HotStarTaq Plus Master Mix Kit (QIAGEN, CA, USA) was used for PCR under the following conditions: $95^{\circ} \mathrm{C}$ for $5 \mathrm{~min}$ followed by 35 cycles of $95^{\circ} \mathrm{C}$ for $30 \mathrm{~s}, 54^{\circ} \mathrm{C}$ for $40 \mathrm{~s}$, and $72^{\circ} \mathrm{C}$ for $1 \mathrm{~min}$, a final elongation step at $72^{\circ} \mathrm{C}$ for $10 \mathrm{~min}$ was also included. The PCR products were cleaned by using Diffinity Rapid Tip (Diffinity Genomics, Inc., West Henrietta, NY, USA), and the small fragments were removed by using Agencourt Ampure Beads (Beckman Coulter, CA, USA). Bacterial tagencoded FLX-Titanium amplicon pyrosequencing (bTEFAP) was performed as described previously (43). In preparation 
for FLX-Titanium sequencing (Roche, Nutley, NJ, USA), DNA fragment sizes and concentration were accurately measured using DNA chips under a Bio-Rad Experion Automated Electrophoresis Station (Bio-Rad Laboratories, CA, USA) and a TBS-380 Fluorometer (Turner Biosystems, CA, USA). A sample of double-stranded DNA, 9.6 million molecules $/ \mathrm{ml}$, with an average size of $625 \mathrm{bp}$ were combined with 9.6 million DNA capture beads, and then amplified by emulsion PCR. After bead recovery and bead enrichment, the bead attached DNAs were denatured with $\mathrm{NaOH}$, and sequencing primers (Roche) were annealed. A four-region 454 sequencing run was performed on a GS PicoTiterPlate (PTP) using the Genome Sequencer FLX System (Roche). Forty tags were used on each quarter region of the PTP. All FLX procedures were performed using Genome Sequencer FLX System manufacturer's instructions (Roche). After denoising (USEARCH application) and chimera removal (UCHIIME in de novo mode), the sequences were clustered into operational taxonomic units clusters with $96.5 \%$ identity $(3.5 \%$ divergence) using USEARCH and the seed sequence put into a FASTA formatted sequence file. The FASTA files were then queried against a database of high quality sequences derived from NCBI using a distributed.NET algorithm that utilizes BLASTN + (KrakenBLAST www.krakenblast.com). The BrayCurtis index (44) and Principal component analyses (PCA) was used to summarize the relationship between microbial communities in the wild-type and IKK $\beta^{\Delta I E C}$ mice. LDA scores were analyzed using the Galaxy software (https://huttenhower. sph.harvard.edu/galaxy/) and the threshold on the logarithmic scale for discriminative features was set at $>2.0$ (45).

\section{Metabolomics}

Metabolite profiles of small intestinal and cecal samples were analyzed by proton nuclear magnetic resonance (NMR). Intestinal scrapings were resuspended in phosphate buffer $(4.3 \mathrm{mM}$ $\mathrm{Na}_{2} \mathrm{HPO}_{4} \cdot 7 \mathrm{H}_{2} \mathrm{O}, 1.5 \mathrm{mM} \mathrm{KH} \mathrm{PO}_{4}, 2.7 \mathrm{mM} \mathrm{KCl}$ ), homogenized, and filtered as described (46). A $70 \mu \mathrm{l}$ aliquot of prepared extract was mixed with $19 \mu \mathrm{l}$ of $9 \mathrm{mM}$ trimethylsilylpropionic-2,2,3,3$\mathrm{d}_{4}$ acid (TSP) in $\mathrm{D}_{2} \mathrm{O}$. The sample was transferred into a micro coaxial NMR tube insert ( $60 \mu \mathrm{l}$ volume, $2.02 \mathrm{~mm}$ OD, Wilmad Lab Glass, Co.), which was then placed inside a $5 \mathrm{~mm}$ NMR tube. Proton $\left({ }^{1} \mathrm{H}\right)$ NMR spectra were acquired at $25^{\circ} \mathrm{C}$ using a Varian INOVA operating at $600 \mathrm{MHz}(14.1 \mathrm{~T})$ as we described previously (47), with an acquisition time of $4 \mathrm{~s}$, interpulse delay of $6.55 \mathrm{~s}$, and 1,680 transients ( $3 \mathrm{~h}$ of signal averaging). Spectra

\section{REFERENCES}

1. Sicherer SH. Epidemiology of food allergy. J Allergy Clin Immunol (2011) 127(3):594-602. doi:10.1016/j.jaci.2010.11.044

2. Tang ML, Mullins RJ. Food allergy: is prevalence increasing? Intern Med J (2017) 47(3):256-61. doi:10.1111/imj.13362

3. Wang J, Liu AH. Food allergies and asthma. Curr Opin Allergy Clin Immunol (2011) 11(3):249-54. doi:10.1097/ACI.0b013e3283464c8e

4. Branum A, Lukacs S. Food allergy among US children: prevalence and hospital visits. Pediatrics (2009) 124(6):1549-55. doi:10.1542/peds.2009-1210

5. Koplin JJ, Mills EN, Allen KJ. Epidemiology of food allergy and foodinduced anaphylaxis: is there really a Western world epidemic? Curr Opin Allergy Clin Immunol (2015) 15(5):409-16. doi:10.1097/ACI. 0000000000000196 were pre-processed using Varian software and were baseline corrected using the Whittaker Smoother algorithm. For multivariate data analyses, spectra were binned to reduce the dimensionality and mitigate peak misalignment (46). A dynamic programmingbased adaptive binning technique was employed (48) using a minimum and maximum distance between peaks in a single bin of 0.001 and $0.04 \mathrm{ppm}$, respectively. Quantification of specific metabolite resonances was accomplished using an interactive spectral deconvolution algorithm in MATLAB (48). All metabolite peak intensities were corrected for equivalent number of protons and normalized relative to the TSP signal intensity. Peaks were assigned to specific metabolites following a previously described procedure (46). To assess metabolome similarity among samples, principal components analysis (PCA) was run on the binned dataset; the intra-group variance was adjusted by Mahalanobis scaling as we did previously (47). Separation of sample groups in PCA ordination space was tested based on the permutation analysis of the Davies-Bouldin index measure (49).

\section{Statistical Analysis}

Results are expressed as the mean \pm 1 SD. Statistical significance was determined by one-way ANOVA, followed by Tukey post hoc test. All statistical analyses were performed with the StataSE 12.0 software (StataCorp LLC, College Station, TX, USA) and Prism 7 software (Graphpad Software, La Jolla, CA, USA).

\section{ETHICS STATEMENT}

Studies were approved by the Institutional Animal Care and Use Committee (IACUC, protocol \#2008A0210) and performed on mice aged 10-12 weeks, in accordance with NIH and OSU IACUC guidelines.

\section{AUTHOR CONTRIBUTIONS}

Designed studies and wrote the manuscript: EK, EC-B, and PB; conducted studies: EK, ML, GF, JR, TM, NR; analyzed data: EK, $\mathrm{NR}, \mathrm{OP}, \mathrm{AS}, \mathrm{EC}-\mathrm{B}$, and PB; edited the manuscript: EK, AS, OP, $\mathrm{EC}-\mathrm{B}$, and $\mathrm{PB}$.

\section{FUNDING}

This work was supported by NIH Grants DK101323 and AI123661 (to $\mathrm{PB}$ ).

6. Simons FE, Ardusso LR, Bilo MB, El-Gamal YM, Ledford DK, Ring J, et al. World allergy organization guidelines for the assessment and management of anaphylaxis. World Allergy Organ J (2011) 4(2):13-37. doi:10.1097/ WOX.0b013e318211496c

7. Saluja R, Khan M, Church MK, Maurer M. The role of IL-33 and mast cells in allergy and inflammation. Clin Transl Allergy (2015) 5:33. doi:10.1186/ s13601-015-0076-5

8. Fort MM, Cheung J, Yen D, Li J, Zurawski SM, Lo S, et al. IL-25 induces IL-4, IL-5, and IL-13 and Th2-associated pathologies in vivo. Immunity (2001) 15(6):985-95. doi:10.1016/S1074-7613(01)00243-6

9. Liew FY, Girard JP, Turnquist HR. Interleukin-33 in health and disease Nat Rev Immunol (2016) 16(11):676-89. doi:10.1038/nri.2016.95

10. Regoli M, Man A, Gicheva N, Dumont A, Ivory K, Pacini A, et al. Morphological and functional characterization of IL-12Rbeta2 chain on intestinal epithelial 
cells: implications for local and systemic immunoregulation. Front Immunol (2018) 9:1177. doi:10.3389/fimmu.2018.01177

11. Gerondakis S, Fulford TS, Messina NL, Grumont RJ. NF-kappaB control of T cell development. Nat Immunol (2014) 15(1):15-25. doi:10.1038/ni.2785

12. Vallabhapurapu S, Karin M. Regulation and function of NF-kappaB transcription factors in the immune system. Annu Rev Immunol (2009) 27:693-733. doi:10.1146/annurev.immunol.021908.132641

13. Bonnegarde-Bernard A, Jee J, Fial MJ, Aeffner F, Cormet-Boyaka E, Davis IC, et al. IKKbeta in intestinal epithelial cells regulates allergen-specific IgA and allergic inflammation at distant mucosal sites. Mucosal Immunol (2014) 7(2):257-67. doi:10.1038/mi.2013.43

14. Dunkin D, Berin MC, Mayer L. Allergic sensitization can be induced via multiple physiologic routes in an adjuvant-dependent manner. J Allergy Clin Immunol (2011) 128(6):1251-8.e2. doi:10.1016/j.jaci.2011.06.007

15. Fischer R, McGhee JR, Vu HL, Atkinson TP, Jackson RJ, Tome D, et al. Oral and nasal sensitization promote distinct immune responses and lung reactivity in a mouse model of peanut allergy. Am J Pathol (2005) 167(6): 1621-30. doi:10.1016/S0002-9440(10)61246-1

16. Boyaka PN. Inducing mucosal IgA: a challenge for vaccine adjuvants and delivery systems. J Immunol (2017) 199(1):9-16. doi:10.4049/jimmunol.1601775

17. Wambre E, James EA, Kwok WW. Characterization of CD4+ T cell subsets in allergy. Curr Opin Immunol (2012) 24(6):700-6. doi:10.1016/j.coi.2012.07.009

18. Nylund L, Nermes M, Isolauri E, Salminen S, de Vos WM, Satokari R. Severity of atopic disease inversely correlates with intestinal microbiota diversity and butyrate-producing bacteria. Allergy (2015) 70(2):241-4. doi:10.1111/ all.12549

19. Wopereis H, Sim K, Shaw A, Warner JO, Knol J, Kroll JS. Intestinal microbiota in infants at high risk for allergy: effects of prebiotics and role in eczema development. J Allergy Clin Immunol (2018) 141(4):1334-42.e5. doi:10.1016/j. jaci.2017.05.054

20. Canani RB, Gilbert JA, Nagler CR. The role of the commensal microbiota in the regulation of tolerance to dietary allergens. Curr Opin Allergy Clin Immunol (2015) 15(3):243-9. doi:10.1097/ACI.0000000000000157

21. Berni Canani R, Sangwan N, Stefka AT, Nocerino R, Paparo L, Aitoro R, et al. Lactobacillus rhamnosus GG-supplemented formula expands butyrateproducing bacterial strains in food allergic infants. ISME J (2015) 10:742. doi:10.1038/ismej.2015.151

22. Cardani D, Dusio GF, Luchini P, Sciarabba M, Solimene U, Rumio C. Oral administration of interleukin-10 and anti-IL-1 antibody ameliorates experimental intestinal inflammation. Gastroenterology Res (2013) 6(4):124-33. doi: $10.4021 /$ gr $556 \mathrm{w}$

23. Cummins JM, Krakowka GS, Thompson CG. Systemic effects of interferons after oral administration in animals and humans. Am J Vet Res (2005) 66(1):164-76. doi:10.2460/ajvr.2005.66.164

24. Gariboldi S, Palazzo M, Zanobbio L, Dusio GF, Mauro V, Solimene U, et al. Low dose oral administration of cytokines for treatment of allergic asthma. Pulm Pharmacol Ther (2009) 22(6):497-510. doi:10.1016/j.pupt. 2009.05.002

25. Rollwagen FM, Davis TA, Li YY, Pacheco ND, Zhu XL. Orally administered IL-6 induces elevated intestinal GM-CSF gene expression and splenic CFU-GM. Cytokine (2004) 27(4-5):107-12. doi:10.1016/j.cyto. 2004.03.019

26. Rollwagen FM, Yu ZY, Li YY, Pacheco ND. IL-6 rescues enterocytes from hemorrhage induced apoptosis in vivo and in vitro by a bcl-2 mediated mechanism. Clin Immunol Immunopathol (1998) 89(3):205-13. doi:10.1006/ clin. 1998.4600

27. Marinaro M, Boyaka PN, Finkelman FD, Kiyono H, Jackson RJ, Jirillo E, et al. Oral but not parenteral interleukin (IL)-12 redirects T helper 2 (Th2)type responses to an oral vaccine without altering mucosal IgA responses. J Exp Med (1997) 185(3):415-27. doi:10.1084/jem.185.3.415

28. Ventura I, Vega A, Chamorro C, Aroca R, Gomez E, Pineda F, et al. Allergen immunotherapy decreases LPS-induced NF-kappaB activation in neutrophils from allergic patients. Pediatr Allergy Immunol (2014) 25(2):129-35. doi:10.1111/pai.12145

29. Zaph C, Troy AE, Taylor BC, Berman-Booty LD, Guild KJ, Du Y, et al. Epithelial-cell-intrinsic IKK-beta expression regulates intestinal immune homeostasis. Nature (2007) 446(7135):552-6. doi:10.1038/nature05590

30. Travers J, Rothenberg ME. Eosinophils in mucosal immune responses. Mucosal Immunol (2015) 8(3):464-75. doi:10.1038/mi.2015.2
31. Ahrens R, Waddell A, Seidu L, Blanchard C, Carey R, Forbes E, et al. Intestinal macrophage/epithelial cell-derived CCL11/eotaxin-1 mediates eosinophil recruitment and function in pediatric ulcerative colitis. JImmunol (2008) 181(10):7390-9. doi:10.4049/jimmunol.181.10.7390

32. Matsukura S, Stellato C, Plitt JR, Bickel C, Miura K, Georas SN, et al. Activation of eotaxin gene transcription by NF-kappa B and STAT6 in human airway epithelial cells. J Immunol (1999) 163(12):6876-83.

33. Waddell A, Ahrens R, Tsai YT, Sherrill JD, Denson LA, Steinbrecher KA, et al. Intestinal CCL11 and eosinophilic inflammation is regulated by myeloid cell-specific RelA/p65 in mice. J Immunol (2013) 190(9):4773-85. doi:10.4049/jimmunol.1200057

34. Yang J, Hawkins OE, Barham W, Gilchuk P, Boothby M, Ayers GD, et al. Myeloid IKKbeta promotes antitumor immunity by modulating CCL11 and the innate immune response. Cancer Res (2014) 74(24):7274-84. doi:10.1158/ 0008-5472.CAN-14-1091

35. Chu VT, Beller A, Rausch S, Strandmark J, Zanker M, Arbach O, et al. Eosinophils promote generation and maintenance of immunoglobulin-Aexpressing plasma cells and contribute to gut immune homeostasis. Immunity (2014) 40(4):582-93. doi:10.1016/j.immuni.2014.02.014

36. Greten FR, Arkan MC, Bollrath J, Hsu LC, Goode J, Miething C, et al. NF-kappaB is a negative regulator of IL-1beta secretion as revealed by genetic and pharmacological inhibition of IKKbeta. Cell (2007) 130(5):918-31. doi:10.1016/j.cell.2007.07.009

37. Chen LW, Egan L, Li ZW, Greten FR, Kagnoff MF, Karin M. The two faces of IKK and NF-kappaB inhibition: prevention of systemic inflammation but increased local injury following intestinal ischemia-reperfusion. Nat Med (2003) 9(5):575-81. doi:10.1038/nm849

38. Duverger A, Jackson RJ, van Ginkel FW, Fischer R, Tafaro A, Leppla SH, et al. Bacillus anthracis edema toxin acts as an adjuvant for mucosal immune responses to nasally administered vaccine antigens. JImmunol (2006) 176(3):1776-83. doi:10.4049/jimmunol.176.3.1776

39. Liu Y, Sun Y, Chang LJ, Li N, Li H, Yu Y, et al. Blockade of peanut allergy with a novel Ara h 2-Fcgamma fusion protein in mice. J Allergy Clin Immunol (2013) 131(1):e1-5. doi:10.1016/j.jaci.2012.10.018

40. Duverger A, Carre JM, Jee J, Leppla SH, Cormet-Boyaka E, Tang WJ, et al. Contributions of edema factor and protective antigen to the induction of protective immunity by Bacillus anthracis edema toxin as an intranasal adjuvant. J Immunol (2010) 185(10):5943-52. doi:10.4049/jimmunol. 0902795

41. Sato T, van Es JH, Snippert HJ, Stange DE, Vries RG, van den Born M, et al. Paneth cells constitute the niche for Lgr5 stem cells in intestinal crypts. Nature (2011) 469(7330):415-8. doi:10.1038/nature09637

42. Sato T, Vries RG, Snippert HJ, van de Wetering M, Barker N, Stange DE, et al. Single Lgr5 stem cells build crypt-villus structures in vitro without a mesenchymal niche. Nature (2009) 459(7244):262-5. doi:10.1038/nature07935

43. Dowd SE, Wolcott RD, Sun Y, McKeehan T, Smith E, Rhoads D. Polymicrobial nature of chronic diabetic foot ulcer biofilm infections determined using bacterial tag encoded FLX amplicon pyrosequencing (bTEFAP). PLoS One (2008) 3(10):e3326. doi:10.1371/journal.pone.0003326

44. Bray JR, Curtis JT. An Ordination of the Upland Forest Communities of Southern Wisconsin. Ecol Monogr (1957) 27(4):326-49. doi:10.2307/ 1942268

45. Segata N, Izard J, Waldron L, Gevers D, Miropolsky L, Garrett WS, et al. Metagenomic biomarker discovery and explanation. Genome Biol (2011) 12(6):R60. doi:10.1186/gb-2011-12-6-r60

46. Shankar V, Homer D, Rigsbee L, Khamis HJ, Michail S, Raymer M, et al. The networks of human gut microbe-metabolite associations are different between health and irritable bowel syndrome. ISME J (2015) 9(8):1899-903. doi:10.1038/ismej.2014.258

47. Shankar V, Gouda M, Moncivaiz J, Gordon A, Reo NV, Hussein L, et al. Differences in gut metabolites and microbial composition and functions between Egyptian and U.S. Children are consistent with their diets. mSystems. (2017) 2(1):e169-116.doi:10.1128/mSystems.00169-16

48. Anderson PE, Mahle DA, Doom TE, Reo NV, DelRaso NJ, Raymer ML. Dynamic adaptive binning: an improved quantification technique for NMR spectroscopic data. Metabolomics (2011) 7(2):179-90. doi:10.1007/s11306010-0242-7

49. Davies DL, Bouldin DW. A cluster separation measure. IEEE Trans Pattern Anal Mach Intell (1979) 1(2):224-7. doi:10.1109/TPAMI.1979.4766909 
Conflict of Interest Statement: The authors declare that the research was conducted in the absence of any commercial or financial relationships that could be construed as a potential conflict of interest.

Copyright (C) 2018 Kim, Lembert, Fallata, Rowe, Martin, Satoskar, Reo, Paliy, Cormet-Boyaka and Boyaka. This is an open-access article distributed under the terms of the Creative Commons Attribution License (CC BY). The use, distribution or reproduction in other forums is permitted, provided the original author(s) and the copyright owner(s) are credited and that the original publication in this journal is cited, in accordance with accepted academic practice. No use, distribution or reproduction is permitted which does not comply with these terms. 